\title{
PNEUMOPERITONEUM-A COMPLICATION OF NASAL OXYGEN THERAPY: A CASE REPORT
}

\section{E A GaIn, $M D^{1}$}

PNEUMOPERTONEUM is usually the result of a perforation of the stomach or bowel by disease or mechanical trauma This type rarely results in tension causing respiratory and circulatory embarrassment. Pneumoperitoneum can follow mediastinal emphysema produced by excessive airway pressure during anaesthesia $(1,2)$; the gas tracking down retroperitoneal and breaking through the peritoneum, but this is very rare (2) Everyone is familiar with the rather frequent error of attaching the oxygen to the gastric suction tube, an accident which is easily recognized

We believe that the following case is of interest because of its rarity and its similarity to a case reported by Fenton (3) of pneumoperitoneum following nasal oxygen therapy.

Mrs S, a healthy 53-year-old female, was prepared for biopsy of a tumour of the right breast and possible radical mastectomy. Anaesthesia was induced with $025 \mathrm{gm}$ Thiopentone followed by $25 \mathrm{mg}$ Meperidine and nitrous oxide-oxygen 4.2 administered by a semi-closed circle absorption system The respirations were assisted throughout but not controlled. There was a fifteen-minute delay between induction and the commencement of surgery With the skin incision mild laryngospasm developed and was easily corrected in a very short time with Thiopentone $0125 \mathrm{gm}$. Meperidine $25 \mathrm{mg}$ increased assistance to respiration The anaesthetist did not consider that excessive pressure was used at this time and it was definitely less than $20 \mathrm{~mm} \mathrm{Hg}$.

At the conclusion of the 20 minutes of surgery respiration was only 6 per minute so Nallme $5 \mathrm{mg}$ was given intravenously The rate increased to 12 per minute and the patient was returned to the recovery room in good condition Nasal oxygen by catheter was ordered in case respiratory depiession should recur The patient arrived in the recovery room and nasal oxygen at 8 litres per minute was commenced at $1140 \mathrm{Am}$ At $1220 \mathrm{PM}$ the recovery room nurse reported that the patient was in shock and not responding as rapidly as was expected, anaesthesia seemed deeper of anything Exammation revealed a deeper state of anaesthesia than one would expect, rapid predommantly thoracic respiration, systolıc blood pressure of 70 and pulse of 74 The skm was pale, dry and cold, the abdomen was grossly distended, tympantic, rigid, and palpation caused some pain-like response At first only gastric distension was suspected, but because of tenderness X-rays were taken of chest and abdomen In the meantıme attempts to pass a gastric tube falled because of an apparent obstruction at the level of the cardia The X-rays revealed a normal chest except for high diaphragms, a massive pneumoperitoneum and a distended stomach but no excess of gas in the small bowel Displacement of the stomach was most probably the reason the gastric tube could not be passed.

1From the Department of Andesthesia, University Hospital and University of Alberta, Edmonton, Alta 
A needle was inserted through the abdominal wall and gas under marked pressure gushed forth, the abdomen collapsed and was then soft with no evider ce of peritoneal irritation The patient's conscious level improved rapidly, indoubtedly because of the improved ventilation, and the blood pressure soon returned to normal levels.

Postoperatively the patient had an elevated temperature $99^{\circ}-101^{\circ}$ ) for two days and shoulder pain, the abdomen remained soft and n st tender, no other evidence of peritonitis occurred and the patient was discharged well after five days of observation.

Two days later the patient was readmitted with the typical signs and symptoms of a left lower lobe pneumonia. Under conventional therapy this resolved rapidly and the patient was discharged and has remaned well. During the last: admission complete radiographic examination of chest, oesophagus and stomach were carried out, no abnormalities other than the resolving pneumonia were discovered.

At the tume of the pneumoperitoneum it was believed that in spite of the anaesthetist's assurance that no excessive pressure had been used in assisting respiration this was the most likely cause of such q massive pneumoperitoneum Fenton's (3) report of a similar case following nasal oxygen therapy was recalled and it is believed that the same sequence of events occurred as described by Fenton (3). She postulated that the nasal oxygen catheter had been inserted below the cricopharyngeus which acted as a true sphincter, and with a relaxed cardia and closed pylorus allowed distension and perforation of the stomach.

At autopsy Fenton's patient showed that the muscle fibres of the stomach were laminated and separated and there was a minute tear in the mucosa and extensive bleeding into the stomach and intestne. Since she does not mention the mode of exit of the oxygen from the stomach into the peritoneal cavity, one must assume a tear on the peritoneal surface of the stomach or intestine. As there was no sign of peritoneal urritation in our patient, it is suggested that possibly the gas had passed beneath the mucosa and out along the vessels of the stomach into the peritoneal cavity, as it does, in a similar manner, in mediastinal emphysema following alveolar rupture due to excessive arrway pressure during anaesthesia $(1,2)$

We cannot feel as absolutely certain of the aetiology in this case as could Fenton (3), an endotracheal tube was not used here and we believe that one could have overlooked the distension because of the surgical drapes and the site of the operation, and the cause therefore could have been excessive mask pressure. On the other hand, we doubt if the patient would have been considered to be in good condition if this distension had been present in the operatifing theatre or on arrival in the recovery room, and therefore the most likely cause was the nasal oxygen.

Measurement of the oxygen flowmeter used revealed that a pressure of $40 \mathrm{~mm}$ $\mathrm{Hg}$ was necessary to open the safety blow-off, this is undoubtedly an excessive pressure and such therapy apparatus should be manufactured to blow-off at a much lower pressure or this complication will continue to occur. Fenton's case resulted from the same fault, in her case a flowmeter was not used, only a simple pin-type valve with no pressure regulation. 
This case açaun emphasizes the dangers of oxygen therapy using a nasal catheter, also tee need for care in placing the catheter correctly and the use of low-pressure controlled flowmeters.

\section{REFERENCES}

1. MACkLIN, C C. Canad M.A.J. 36: 414 (1937).

2. Spence, M. Anaesthesia 10:50 (1955)

3 Fenton, C S N Bnt J Anaesth 28220 (1956). 